\title{
PENGENDALIAN KEBAKARAN HUTAN DI KPH SUMEDANG
}

\author{
Forest and Land Fires Control in KPH Sumedang \\ Bambang Hero Saharjo ${ }^{1 *}$ dan Fakhri Sukma Afina ${ }^{2}$
}

(Diterima November 2020/Disetujui April 2021)

\begin{abstract}
Forest fire is one of the most common forest disturbances. The losses incurred will continue to increase if there is no control efforts are taken. Forest fires in KPH Sumedang in 2014 occur as many as ten times with varied sites including Tomo Utara, Ujung Jaya, Cadas Pangeran, and Tomo, therefore it is necessary to analyze the causes of fire and forest fire control efforts need to be undertaken. This research was conducted by using data triangulation method, and qualitative descriptive analysis. The results showed the cause of the fire due to factors surrounding community activities include forest clearance of land, cigarette butts and land clearing by burning. Forest fire suppression facilities and infrastructure available at KPH Sumedang still do not meet the requirements set forth in LHK Regulation No. 32 of 2016, it is concluded that the efforts already taken to overcome forest fire in KPH Sumedang is not optimal.
\end{abstract}

Keywords: blackout facilities, causes of forest fires, infrastructure, and forest fires

\section{PENDAHULUAN}

Kebakaran hutan merupakan salah satu gangguan hutan yang sering terjadi. Kebakaran hutan menurut Saharjo (2003) merupakan kejadian pembakaran yang penjalarannya bebas pada areal yang tidak direncanakan serta mengonsumsi bahan bakar alam dari hutan seperti serasah, rumput, ranting/cabang pohon mati, pohon mati yang tetap berdiri, log, tunggak pohon, gulma, semak belukar, dedaunan dan pohon-pohon. Kebakaran hutan Indonesia terbesar terjadi pada tahun 1997/1998 yang menghanguskan 9.7 juta ha (Applegate dan Suyanto 2001).

Kerugian yang ditimbulkan dari kebakaran hutan akan terus meningkat apabila tidak dilakukan upaya pencegahan serta pengendalian sejak dini. Kejadian kebakaran hutan di Indonesia sering terjadi pada musim kemarau, tidak terkecuali di KPH Sumedang. Berdasarkan media berita sinar pagi aktual, kasus kejadian kebakaran hutan tahun 2014 telah terjadi sebanyak sepuluh kali dengan tempat yang bervariasi yaitu di Tomo utara, Ujung Jaya, Cadas Pangeran, dan yang terakhir di Tomo.

Peranan sarana dan prasarana pemadam kebakaran sangat di perlukan dalam upaya pencegahan, namun banyak fakta di lapangan menemukan keberadaan sarana dan prasarana tersebut kurang memadai. Menurut Saharjo (2016) tahun 2014 telah dilaksanakan audit kepatuhan terkait upaya pengendalian kebakaran yang dilakukan oleh 15 korporasi yang bergerak dalam bidang kehutanan (HTI dan HF serta HHBK-Sago) dan kelapa

\footnotetext{
${ }^{1}$ Dosen Departemen Silvikultur, Fakultas Kehutanan dan Lingkungan, IPB University

* Penulis korespondensi:

e-mail: saharjobambangh@gmail.com

2 Mahasiswa Departemen Silvikultur, Fakultas Kehutanan dan Lingkungan, IPB University
}

sawit di Provinsi Riau. Hasil audit memastikan bahwa tidak ada satu pun dari 15 korporasi tersebut termasuk mereka yang selalu menyatakan sangat peduli lingkungan dan memiliki peralatan yang sangat memadai dalam mengendalikan kebakaran terbukti tidak mematuhi janji yang mereka buat sendiri ketika izin diberikan. Sehubungan dengan kejadian tersebut, maka diperlukan analisis mengenai penyebab terjadinya kebakaran, serta ketersediaan sarana dan prasarana dalam upaya pemadaman kebakaran hutan sehingga dapat dilakukan upaya pengendalian secara optimal oleh pihak KPH Sumedang.

Tujuan penelitian ini adalah untuk menganalisis hubungan antara faktor penyebab terjadinya kebakaran hutan dan ketersediaan sarana dan prasarana penunjang dalam upaya pengendalian kebakaran hutan di Perum Perhutani KPH Sumedang. Hasil penelitian ini diharapkan dapat memberikan informasi tentang penyebab terjadinya kebakaran, serta pentingnya keberadaan sarana dan prasarana pengendalian kebakaran dalam membantu upaya pengendalian khususnya yang dilakukan oleh Perhutani KPH Sumedang.

\section{METODE PENELITIAN}

\section{Waktu dan Lokasi Penelitian}

Penelitian ini dilakukan di Perum Perhutani KPH Sumedang, BKPH Tomo Utara pada bulan April 2017.

\section{Alat dan Bahan}

Alat yang digunakan dalam penelitian ini adalah perangkat laptop, lembar kuesioner (tally sheet), alat tulis, kamera dan alat perekam. Bahan dan data yang diperlukan dalam penelitian yaitu data kondisi umum KPH Sumedang, data frekuensi/jumlah kebakaran hutan 
selama 5 (lima) tahun terakhir (2012-2016), data curah hujan 5 (lima) tahun terakhir (2012-2016), data luas kebakaran hutan 5 (lima) tahun terakhir (2012-2016), dan data pengelolaan hutan dalam pengendalian kebakaran hutan data inventarisasi sarana dan prasarana.

\section{Prosedur Penelitian}

\section{Penentuan Lokasi Penelitian}

Lokasi ditentukan dengan menggunakan metode purposive sampling berdasarkan pada tingkat kejadian kebakaran hutan di KPH Sumedang.

\section{Penentuan Responden}

Penentuan responden dilakukan dengan metode snowball sampling technique, dimana peneliti pada awalnya mengenal responden kunci (key person interviews) kemudian responden kunci akan memperkenalkan kepada responden lain (Bungin 2011). Responden kunci (key person interviews) dalam penelitian ini yaitu Danru KPH Sumedang, Personil BKPH Tomo Utara. Responden lain yaitu masyarakat yang berada di desa Tomo dengan Desa Cipeles. Wawancara dilakukan dengan subjek mendatangi langsung responden dan mengambil kesempatan yang memudahkan untuk wawancara (Muhadjir 1992).

\section{Analisis Sarana dan Prasarana}

Analisis sarana dan prasarana dilakukan dengan penelusuran dokumen serta kondisi di lapangan yaitu dengan melakukan wawancara pihak KPH Sumedang dan hasil tersebut disesuaikan dengan kriteria kepatuhan berdasarkan klasifikasi pada Permen LHK No. 32 tahun 2016 yang tersaji pada Tabel 1.

\section{Pengumpulan Data}

Data yang digunakan dalam penelitian ini meliputi data primer dan data sekunder. Data primer diperoleh melalui metode wawancara dan observasi lapang. Wawancara dilakukan dengan pihak KPH Sumedang. Data sekunder diperoleh melalui penelusuran dokumen agar didapatkan dokumen yang berkaitan dengan penyebab kebakaran dan upaya pengendalian kebakaran

Tabel 1. Klasifikasi kategori kepatuhan

\begin{tabular}{lc}
\hline \multicolumn{1}{c}{ Kriteria } & Selang \\
\hline Patuh & $85-100$ \\
Cukup patuh & $65-85$ \\
Kurang patuh & $50-60$ \\
Tidak patuh & $<50$ \\
\hline
\end{tabular}

Sumber : Permen LHK No. 32 Tahun 2016

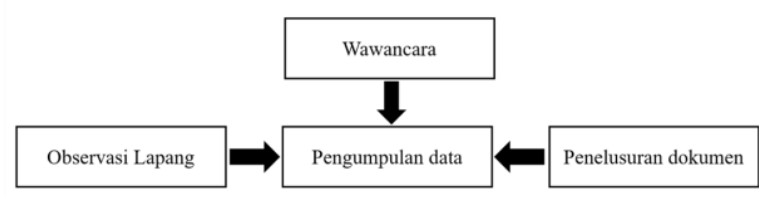

Gambar 1. Triangulasi metode pengumpulan data (Sitorus 1998) di KPH Sumedang. Metode pengumpulan data yang digunakan dapat digambarkan dengan metode triangulasi yang mencakup metode lainnya. Teknik pengumpulan data ditunjukkan pada Gambar 1 berikut ini:

\section{Analisis Data}

Metode analisis data yang digunakan adalah metode analisis deskriptif kualitatif yaitu dengan mendeskripsikan secara menyeluruh data yang di dapat. Analisis data deskriptif kualitatif ini menggunakan model Miles dan Huberman yang meliputi data reduction (reduksi data), data display (penyajian data), dan data conclusion drawing/verification (penarikan kesimpulan). Model interaktif analisis data ditunjukkan pada Gambar 2 berikut :

\section{HASIL DAN PEMBAHASAN}

\section{Kondisi Umum Lokasi Penelitian}

Menurut laporan semester II RKL - RPL KPH Sumedang tahun 2015, areal kerja KPH Sumedang secara geografis atau berdasarkan garis lintang, terletak pada $06^{\circ} 40^{\prime}$ LS sampai $70^{\circ} 83^{\prime}$ ' LS dan $107^{\circ} 14^{\prime}$ BT sampai $108^{0} 21^{\prime}$ BT. Wilayah administratif KPH Sumedang mempunyai luasan 37579.45 ha

Berdasarkan pembagian wilayah secara administratif pemerintahan, wilayah KPH Sumedang berada pada wilayah Kabupaten Sumedang Provinsi Jawa Barat, adapun batas wilayah KPH Sumedang meliputi (Laporan Semeter II RKL-RPL KPH Sumedang 2015)

1. Sebelah Utara : Kabupaten Indramayu dan Kabupaten Majalengka

2. Sebelah Timur : Kabupaten Majalengka

3. Sebelah Selatan : Kabupaten Bandung dan Kabupaten Garut

4. Sebelah Barat : Kabupaten Subang.

\section{Kejadian Kebakaran Hutan dan Lahan di KPH Sumedang}

Kebakaran hutan pada kawasan Perum Perhutani KPH Sumedang tercatat dengan total luasan $1.425,19$ ha dalam kurun waktu 2012-2016. Kebakaran hutan yang terjadi pada tahun 2012 merupakan kebakaran dengan luasan tertinggi tercatat seluas 803,10 ha, pada tahun 2013 seluas 239,09 ha, tahun 2014 seluas 226,00 ha, pada tahun 2015 seluas 157,00 dan pada tahun 2016 tidak terjadi kebakaran.

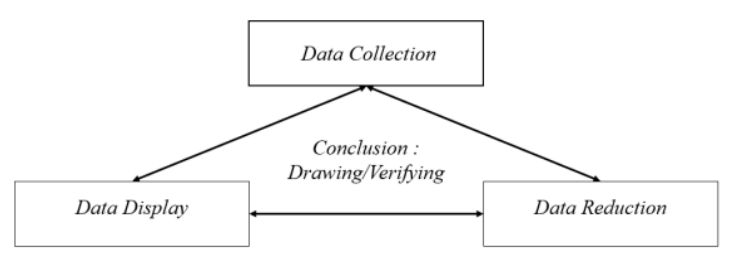

Gambar 2. Komponen analisis data kualitatif model Miles dan Huberman (Sugiyono 2005) 
KPH Sumedang memiliki 9 BKPH yang terdiri dari BKPH Songgom, BKPH Buahdua, BKPH Conggeang, BKPH Ujungjaya, BKPH Tomo Utara, BKPH Tomo Selatan, BKPH Cadasngampar, BKPH Manglayang Timur, dan BKPH Tampomas. BKPH yang memiliki tingkat kebakaran hutan tertinggi yaitu BKPH Tomo Selatan, selanjutnya BKPH Ujungjaya dan setelah itu BKPH Tomo Utara (Gambar 4). BKPH Tomo Utara merupakan tempat yang dijadikan lokasi penelitian dikarenakan lokasi dan aksesibilitas yang mudah untuk di jangkau.

\section{Kebakaran Hutan dan Lahan di BKPH Tomo}

Kejadian kebakaran hutan dan lahan yang terjadi di Desa Tomo Utara tercatat yang tertinggi terjadi pada tahun 2012 dengan total seluas 144,8 ha yang mengakibatkan kerugian finansial sebesar $\mathrm{Rp} 430,950$ (x1000), diikuti tahun 2014 dengan total luasan 47,9 ha mengakibatkan kerugian finansial sebesar Rp 135,850 (x1000), tahun 2013 seluas 41,59 ha dengan kerugian finansial sebesar Rp 124,770 (x1000), tahun 2015 total areal terbakar seluas 7,54 ha dengan kerugian finansial sebesar Rp 567 (x1000) dan pada tahun 2016 tidak terjadi kebakaran hutan.

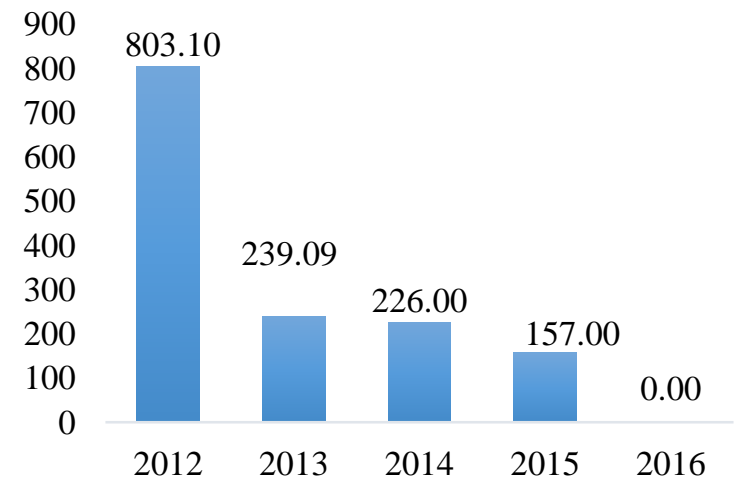

Gambar 3 Luasan kebakaran di KPH Sumedang periode 2012-2016

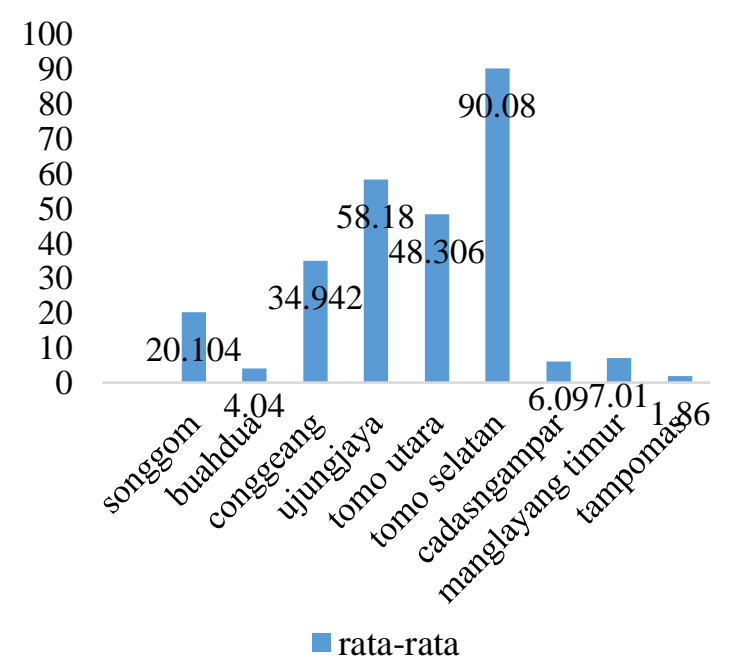

Gambar 4 Luasan kebakaran hutan di setiap BKPH
Curah hujan yang terjadi dalam kurun waktu 5 tahun terakhir (2012-2016) tercatat tertinggi pada tahun 2016 yaitu dengan rata-rata $3039,2 \mathrm{~mm}$ dan terendah yaitu pada tahun 2015 sebesar 2180,5 mm. Tingginya curah hujan berpengaruh terhadap terjadinya kebakaran hutan di wilayah tersebut. Terlihat pada tahun 2012 dan pada tahun 2016 dimana tinggi serta rendahnya luasan terbakar berbanding lurus dengan rendah dan tingginya curah hujan yang terjadi pada tahun tersebut. Berdasarkan klasifikasi Septicorini (2006) tingkat curah hujan lebih dari $2000 \mathrm{~mm} /$ tahun memiliki kelas kerawanan rendah terhadap kebakaran hutan dan lahan, dikarenakan merupakan iklim basah, sehingga berpengaruh terhadap kelembapan regional hutan.

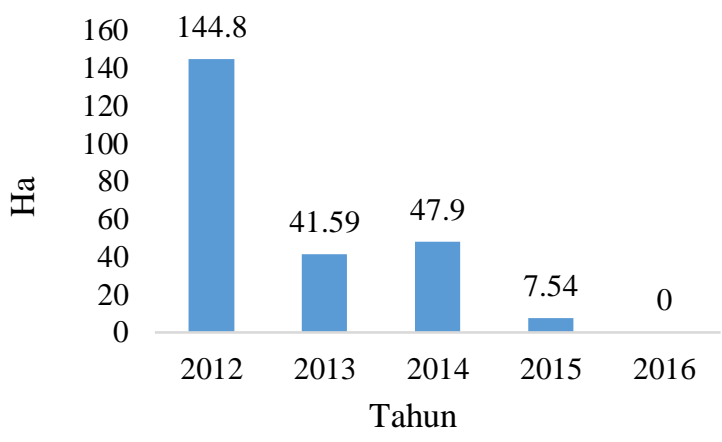

Gambar 5 Luasan Kebakaran hutan di BKPH Tomo Utara periode 2012-2016

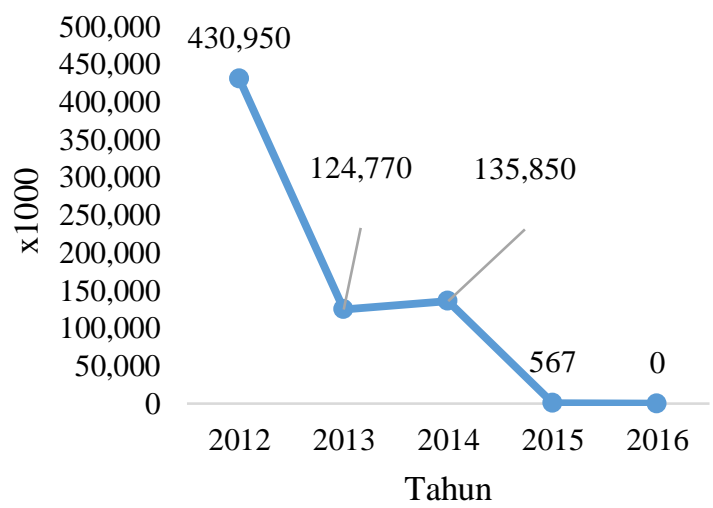

Gambar 6 Kerugian yang diakibatkan kebakaran di BKPH Tomo Utara

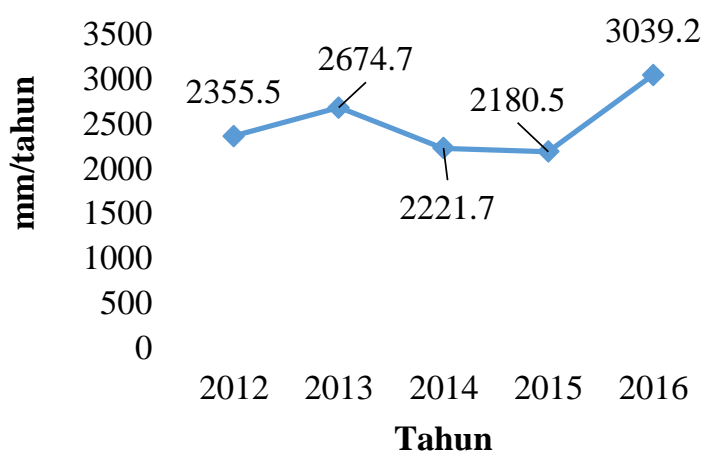

Gambar 7 Kondisi curah hujan periode tahun 20122016 
Kejadian kebakaran hutan dan lahan di BKPH Tomo Utara terjadi pada rentan bulan Juli hingga Oktober, dimana pada bulan tersebut tingkat curah hujan rendah, sehingga memicu kebakaran dengan mudah dikarenakan ketersediaan bahan bakar yang melimpah. Menurut Syaufina (2008) frekuensi dan luas kebakaran tertinggi terjadi pada bulan dengan curah hujan yang rendah (kurang dari $60 \mathrm{~mm} /$ tahun). Curah hujan berpengaruh terhadap kelembapan regional hutan, khususnya terhadap bahan bakar. Curah hujan yang rendah membuat kelembaban bahan bakar rendah dan kadar air pun rendah sehingga potensi kebakaran pada periode bulan Juli hingga Oktober tinggi, seperti yang terdapat pada Gambar 8.

\section{Sumber Penyebab Terjadinya Kebakaran Hutan}

Kebakaran hutan secara umum disebabkan oleh dua faktor, yaitu faktor alam dan faktor manusia. Faktor alam dapat terjadi karena petir, batu bara, dan letusan gunung berapi. Sedangkan faktor manusia antara lain disebabkan oleh kesengajaan membakar, konflik sosial, api unggun dan operasi pembalakan (Sahardjo 2003). Berdasarkan hasil wawancara dengan masyarakat di dua desa yaitu Desa Tomo dengan Desa Cipeles persepsi tentang penyebab terjadinya kebakaran tidak lepas dari kegiatan masyarakat yang berada pada kawasan sekitar hutan. Hasil wawancara terkait persepsi masyarakat mengenai penyebab terjadinya kebakaran dapat dilihat pada Gambar 9.

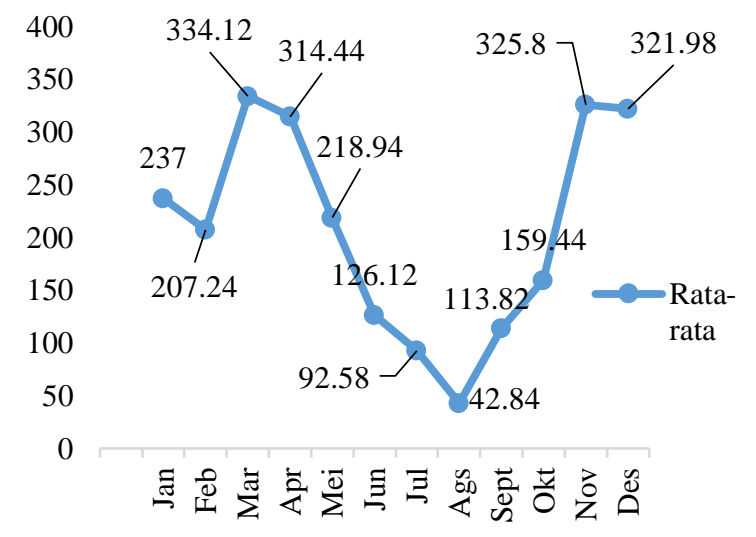

Gambar 8 Rata-rata curah hujan bulanan BKPH Tomo Utara

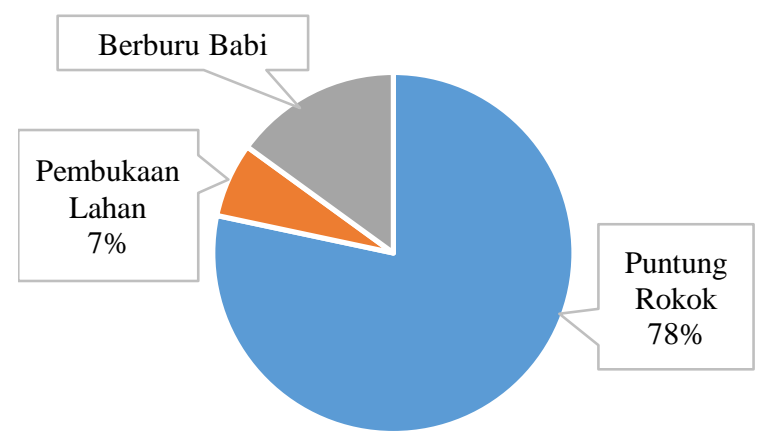

Gambar 9 Persentase persepsi masyarakat
Sebanyak 78 persen responden masyarakat berpendapat bahwa penyebab kebakaran berasal dari puntung rokok yang dibuang sembarangan oleh masyarakat yang menggembala di sekitar hutan. Penggembala biasanya merokok sembari menunggu ternak mereka, bahkan tidak jarang mereka juga membawa obat nyamuk bakar agar melindungi diri mereka dari nyamuk. Menurut Susanty (2014) bahwa puntung rokok tidak dapat menyebabkan kebakaran hutan dan lahan karena puntung rokok tersebut tidak cukup panas untuk memanaskan bahan bakar sampai titik nyala, sehingga dapat dikatakan puntung rokok tidak dapat dikatakan sebagai penyebab terjadinya kebakaran.

Sebanyak 15 persen responden mengatakan bahwa penyebab terjadinya kebakaran hutan dikarenakan oleh adanya kegiatan berburu babi pada kawasan hutan. Kegiatan ini masih sering dilakukan dikarenakan babi dianggap hama yang sering merusak perkebunan mereka. Cara yang digunakan dalam berburu ini salah satunya yaitu melakukan pembakaran pada semak-semak agar mengarahkan hewan buruan pada perangkap. Kejadian tersebut dapat menimbulkan penjalaran api pada kawasan lain dikarenakan api tidak dapat dikendalikan. Selain itu, penyebab terjadinya kebakaran sebanyak 7 persen responden mengatakan dikarenakan pembukaan lahan dengan metode pembakaran. Metode tersebut dianggap lebih efektif serta murah, sehingga masyarakat masih sering melakukan hal tersebut khususnya pada kawasan hutan.

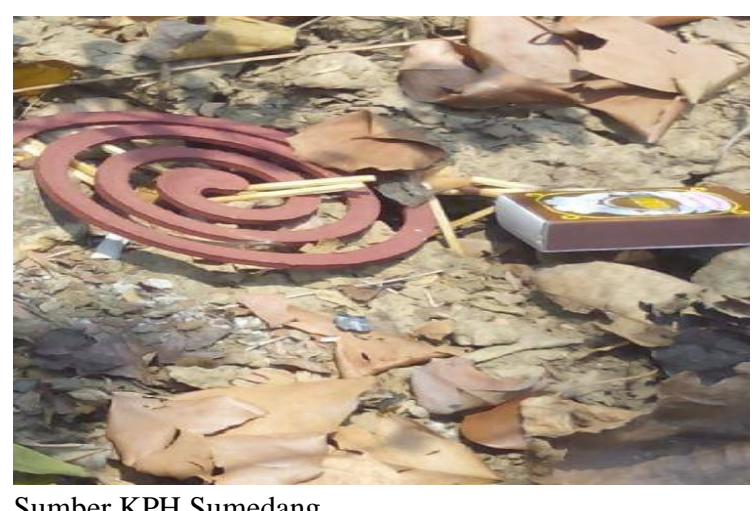

Sumber KPH Sumedang

Gambar 10 Benda yang tertinggal pada lokasi kebakaran

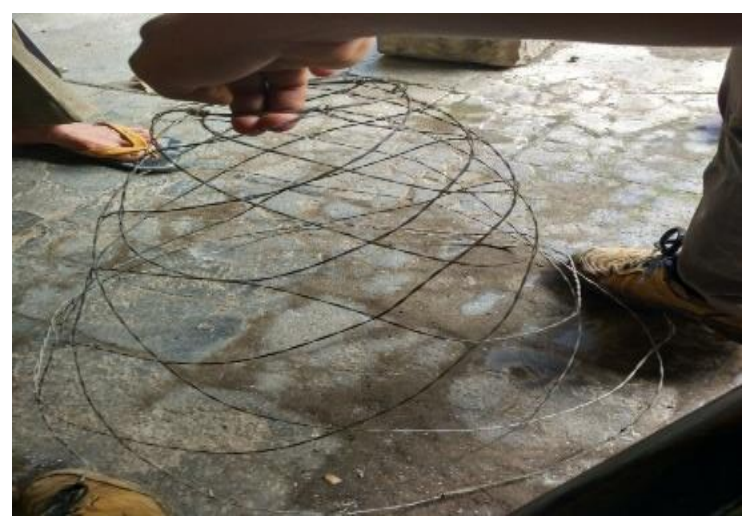

Gambar 11 Perangkap berburu babi 


\section{Sarana dan Prasarana Pemadaman KPH Sumedang}

Upaya pengendalian kebakaran hutan dan lahan, perlu di tunjang dengan adanya sarana dan prasarana untuk mendukung keberhasilan dalam upaya pengendalian tersebut. Sarana dan prasarana yang selanjutnya disingkat sarana prasarana adalah peralatan dan fasilitas yang digunakan untuk mendukung pengendalian kebakaran hutan dan lahan (Permen LHK No. 32 Tahun 2016). Sarana dan prasarana pemadam kebakaran hutan pada unit pengelolaan berdasarkan pada pasal 53 Permen LHK No. 32 Tahun 2016 meliputi (a). Perlengkapan pribadi, (b). Perlengkapan regu, (c). Peralatan regu, (d) Kendaraan khusus pengendalian kebakaran hutan roda empat, (e). Sarana pengolahan data dan komunikasi, dan (f). Sarana transportasi. Ketentuan tersebut dijabarkan kembali pada pasal 54 yang disebutkan bahwa perlengkapan pribadi sebagaimana dimaksud dalam pasal 53 huruf a, sekurang-kurangnya terdiri atas, topi pengaman, lampu kepala, kacamata pengaman, masker dan penutup leher, sarung tangan, sabuk pedples, peluit, ransel, sepatu pemadam, baju pemadam, kaos, kantong tidur, dan ransel standar yang masing-masing perlengkapan sejumlah 15 (lima belas) set.

Sarana dan prasarana pribadi yang tersedia pada KPH Sumedang berdasarkan hasil penelusuran di lapangan tidak ditemukan satu pun alat penunjang. Poin perlengkapan regu berdasarkan ketentuan Permen LHK No. 32 Tahun 2016 pasal 55 ayat 1 terdiri atas (a) 2 (dua) unit tenda, (b) 1 (satu) set peralatan standar perbengkelan, (c) 2 (dua) unit peralatan Standar P3K, dan (d) 1 (satu) unit peralatan penerangan, 1 (satu) unti peralatan masak, dan 1 (satu) unit perlengkapan standar evakuasi dan penyelamatan sederhana. Hasil yang didapatkan bahwa untuk kriteria ketentuan perlengkapan regu tidak ditemukan di lapangan.

Peralatan selanjutnya yaitu peralatan regu, yang kemudian dijabarkan menjadi dua bagian yaitu peralatan tangan dan peralatan mekanis. Peralatan tangan regu yang dimana pada peralatan regu tersebut berdasarkan pada Permen LHK No. 32 Tahun 2016 pasal 56 ayat 3 disebutkan bahwa ketentuan peralatan tangan, dalam 1 (satu) regu sekurang-kurangnya terdiri dari (a) Kapak

Tabel 2. Persentase ketersediaan sarana dan prasarana pengendalian kebakaran di KPH Sumedang

\begin{tabular}{lccc}
\hline $\begin{array}{c}\text { Sarana dan } \\
\text { prasarana } \\
\text { pemadaman }\end{array}$ & $\begin{array}{c}\text { Ketersediaan } \\
\text { alat }\end{array}$ & Ketentuan & $\begin{array}{c}\text { Persentase } \\
\%\end{array}$ \\
\hline $\begin{array}{l}\text { Perlengkapan } \\
\text { pribadi }\end{array}$ & 0 & 9 & \\
$\begin{array}{l}\text { Peralatan } \\
\text { tangan regu }\end{array}$ & 0 & 9 & \\
$\begin{array}{l}\text { Peralatan } \\
\text { mekanis regu }\end{array}$ & 2 & 8 & \\
$\begin{array}{l}\text { Perlengkapan } \\
\text { regu }\end{array}$ & 0 & 6 & 13,15789 \\
$\begin{array}{l}\text { sarana } \\
\text { transportasi }\end{array}$ & 2 & 2 & \\
$\begin{array}{l}\text { Pengolahan } \\
\text { data dan }\end{array}$ & & & \\
komunikasi & 1 & 4 & \\
Jumlah & 5 & 38 & \\
\hline
\end{tabular}

dua fungsi sejumlah 4 (empat) unit, (b) Gepyok sejumlah 8 (delapan) unit, (c) Garu tajam sejumlah 6 ( enam) unit, (d) Garu pacul sejumlah 3 (tiga) unit, (e) Sekop sejumlah 6 (enam) unit, (f) Pompa punggung sejumlah 10 (sepuluh) unit, (g) Obor sulut tetes sejumlah 1 (satu) unit, (h) Kikir sejumlah 2 (dua) unit, (i) Golok/parang sejumlah 10 (sepuluh) unit, yang dimana telah dijabarkan kembali pada ayat 4 mengenai standarisasi untuk masing-masing jenis peralatan tangan sesuai dengan ketentuan peraturan perundang-undangan.

Hasil penelusuran lapang tidak ditemukan Sarana dan prasarana penunjang di KPH Sumedang. Peralatan mekanis berdasarkan ketentuan bahwa, dalam 1 (satu) regu sekurang-kurangnya terdiri atas (a) Pompa induk 1(satu) unit, (b) Pompa jinjing 3 (tiga) unit, (c) Pompa apung 2 (dua) unit, (d) Nozzle 5 (lima) unit, (e) Suntikan Gambut 5 (lima) unit, (f) Tangki air lipat 5 (lima) unit, (g) Selang 50 buah, (h) Chain-saw 1 (satu) unit. Hasil dari penelusuran di lapangan didapatkan sejumlah peralatan yaitu pompa induk sejumlah 1 (satu) unit dan Pompa jinjing sejumlah 25( unit).

Peralatan penunjang pengolahan data dan komunikasi berdasarkan ketentuan yang di atur dalam Permen LHK No. 32 tahun 2016 pasal 59 sekurangkurangnya terdiri atas (a) GPS 1 (satu) unit, (b) Radio
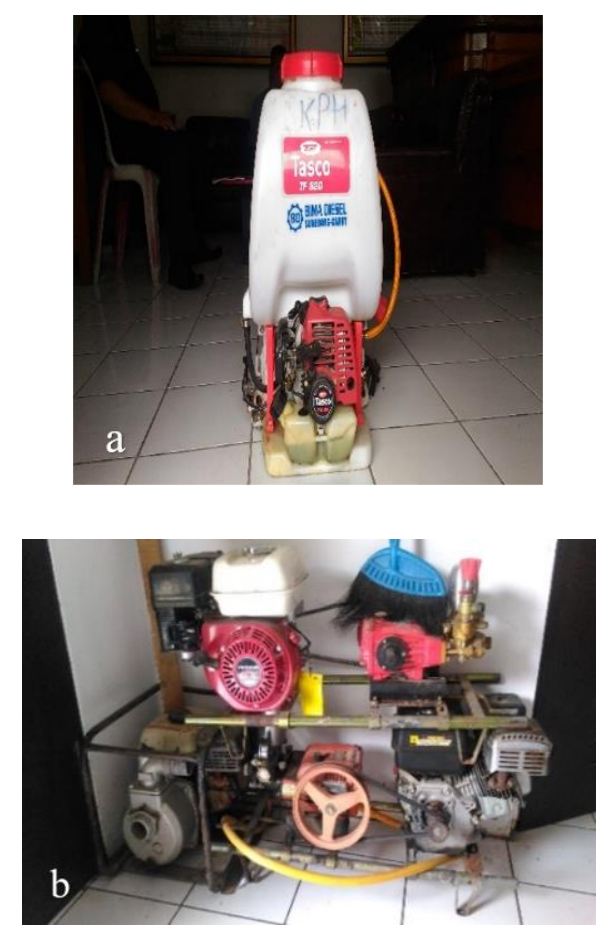

Gambar 12 (a) Pompa jinjing, (b) Pompa induk

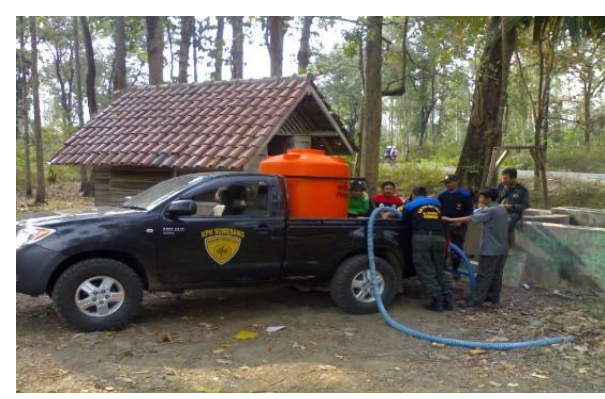

Gambar 13 Sarana transportasi modifikasi 
genggam 4 (empat) unit, (c) Radio mobil 1 (satu), (d) Megaphone 1 (satu). Berdasarkan hasil temuan hanya ditemukan satu alat yaitu radio genggam sebanyak 11 (sebelas) buah. Sarana transportasi yang tersedia di KPH Sumedang berdasarkan hasil penelusuran didapatkan 2 (dua) unit kendaraan roda dua dan 1 (satu) unit kendaraan mobil dinas. Kendaraan mobil dinas tersebut dapat dimodifikasi sedemikian rupa sehingga dapat menunjang saat terjadi kebakaran hutan. Temuan tersebut sesuai dengan ketentuan Permen LHK No. 32 tahun 2016 yang dimana disebutkan dalam pasal 60 bahwa jenis dan jumlah sarana transportasi sebagaimana dimaksud dalam pasal 53 huruf f dalam 1 (satu) regu sekurang-kurangnya terdiri atas (a) kendaraan roda dua jenis lapangan 2 (dua) unit, (b) kendaraan roda empat 2 (dua) unit, (c) sarana transportasi lain.

Hasil temuan berdasarkan Tabel 2 menunjukkan bahwa tingkat keberadaan sarana dan prasarana di KPH Sumedang hanya sebesar $13,15 \%$. Menurut Permen LHK No. 32 tahun 2016 Pasal 105 ayat 2 bahwa kategori kepatuhan mengikuti penilaian (a) Patuh, dengan selang nilai hasil uji 85 sampai dengan 100, (b) Cukup patuh, dengan selang nilai uji 65 sampai kurang dari 85, (c) kurang patuh, dengan selang nilai uji 50 sampai dengan kurang dari 65, (d) Tidak patuh, dengan selang nilai kurang dari 50. Berdasarkan kategori tersebut KPH Sumedang dianggap tidak patuh terhadap peraturan yang berlaku mengenai ketersediaan sarana dan prasarana pemadam kebakaran.

Minimnya keberadaan sarana dan prasarana tersebut berpengaruh terhadap proses pengendalian kebakaran hutan dan lahan yang terjadi, sehingga upaya yang dilakukan dalam rangka meminimalisir kebakaran hutan dan lahan oleh pihak Perhutani dapat dikatakan masih belum optimal.

\section{SIMPULAN DAN SARAN}

\section{Simpulan}

Kebakaran hutan dan lahan yang terjadi di KPH Sumedang di pengaruhi oleh beberapa faktor yaitu curah hujan yang terjadi selama lima tahun terakhir, kegiatan masyarakat yang melakukan pembakaran secara sengaja pada kegiatan berupa berburu babi dan pembukaan lahan. Pihak KPH Sumedang masih belum memenuhi persyaratan yang wajib mereka miliki sesuai Permen LHK No. 32 Tahun 2016 mengenai pemenuhan sarana dan sarana kebakaran hutan, sehingga upaya pengendalian kebakaran hutan yang terjadi masih belum optimal.

\section{Saran}

Perlunya edukasi terhadap masyarakat sehingga dapat mengurangi aktivitas pemburuan dengan cara pembakaran. Selain itu, diperlukan pemenuhan inventarisasi sarana dan prasarana penunjang pengendalian kebakaran hutan dan lahan agar upaya pengendalian berjalan optimal.

\section{DAFTAR PUSTAKA}

Applegate, G., U. Chokkalingam and S. Suyanto. 2001. The Undering causes and im pacts of fires in South-east Asia. CIFOR/ICRAF final Report.

Bungin B. 2011. Penelitian Kualitatif: Komunikasi, Ekonomi, Kebijakan Publik dan Ilmu Sosial Lainnya. Jakarta (ID) : Kencanan Prenada Media Group.

Muhadjir N. 1992. Metodologi Penelitian Kualitatif. Telaah Positivistik, Rasionalistik, Phenomenologik, Realisme Metaphisik. Yogyakarta (ID) : Penerbit Rake Sarasin.

Peraturan Menteri Lingkungan Hidup dan Kehutanan Republik Indonesia Nomor: P.32/MenLHK/ Setjen/Kum.1/3/2016. Tentang Pengendalian Kebakaran Hutan dan Lahan. Jakarta (ID): Kementrian Lingkungan Hidup dan Kehutanan.

[PERHUTANI] Perum Perhutani KPH Sumedang. 2015. Laporan Semeter II RKL-RPL KPH Sumedang. Sumedang (ID) : KPH Sumedang.

Saharjo BH. 2003. Sumber Api. Pengetahuan Dasar Pengendalian Kebakaran Hutan. Bogor (ID) : Fakultas Kehutanan IPB.

Saharjo BH. 2016. Pengendalian Kebakaran Hutan dan atau Lahan Indonesia. Bogor (ID) : IPB Press.

Septicorini EP. 2006. Studi penentuan tingkat kerawanan kebakaran hutan di Kabupaten Ogan Komering Ilir Provinsi Sumatra Selatan [Skripsi]. Bogor (ID) : Institut Pertanian Bogor.

Sinarpagiaktual. 2014. Kebakaran Hutan Rutin Terjadi Dugaan Jadi 'Proyek', Tahunan di Sangkal Perhutani. Sinarpagiaktual.com [Internet] [diunduh 2017 Feb 16]; Tersedia pada: http://www.sinarpagiaktual.net/peristiwa/kebakar an-hutan-rutin-terjadi-dugaan-jadi-proyektahunan-disangkal-perhutani.

Sitorus MTF. 1998. Penelitian Kualitatif : Suatu Perkenalan. Bogor (ID) : Dokis.

Sugiyono. 2005. Memahami Penelitian Kualitatif. Bandung (ID) : CV Alfabeta.

Susanty SC. 2009. Potensi kebakaran hutan di Taman Nasional Gunung Gede Pangrango berdasarkan curah hujan dan sumber api [skripsi]. Bogor (ID) : Institut Pertanian Bogor.

Syaufina L.2008. Kebakaran Hutan dan Lahan di Indoneisa, Perilaku Api, Penyebab dan Dampak Kebakaran. Malang (ID) : Bayumedia. 